\title{
A Glimpse at the Culture of Qajar Era - Public Attraction to Gambling in Qajar Era
}

\author{
Hassan Ziari ${ }^{1} \&$ Mohsen Mohammadi Fesharaki ${ }^{1}$ \\ ${ }^{1}$ Persian Language \& Literature, University of Isfahan, Isfahan, Iran \\ Correspondence: Hassan Ziari, Persian Language \& Literature, University of Isfahan, Isfahan, Iran. Tel: \\ 98-311-793-2171. E-mail: Hasan.ziari@gmail.com
}

Received: September 24, 2012 Accepted: October 23, 2012 Online Published: December 28, 2012

doi:10.5539/ach.v5n1p66 URL: http://dx.doi.org/10.5539/ach.v5n1p66

\begin{abstract}
Games are among cultural manifestations of human communities which have continued to exist since the ancient times and developed during peaceful times; in the Qajar era, during the reign of Nasser-al-Din Shah, because relative peace and prosperity was brought about, the people, especially courtiers, showed great interest in games and spent some of their daily life on it.

In this article we have attempted to present some of the angles and dimensions of a number of these games using the itineraries of orientalists and histories and works of that period. In this regard, we have borne in mind time, venue, extensiveness, customs and the reflection of these games in literature and based on evidences demonstrated that Qajar era is one of the most prominent periods in Iranian history and culture regarding the diversity and colorfulness of these games.

Skillfulness of game players, large bets, struggles and arguments between opponents, special formalities, etc., are all the criteria for the acceptability and popularity of games in this age, which have been put into consideration.
\end{abstract}

Keywords: Qajar era, customs, gambling, Ghomarnameh, playing aces (aas bazi)

\section{Introduction}

In the past, when games were not as variegated, people were compelled to play games to spend their free time and be entertained. Games have existed since the ancient times and have not developed recently; for instance, qaap-bazi goes back to the millennia before Christ and "backgammon has been discovered in the excavations around Nineveh." (Durant, 1989) The persistent presence of games in the course of history, particularly around Iran about which no comprehensive research has been done, makes their investigation and analysis necessary.

Due to relative stability and peace during the reign of Nasser-al-Din Shah (1847-1895), the aristocrats and the well-to-do class allocated some of their time to entertainment. Doubtlessly, as the sources indicate, Nasser-al-Din Shah was the person who encouraged and organized most of these games. It was the same inclinations which resulted in the writing of Ghomarnameh essay. One Qajar prince, named Muhammad Amin Mirza, writes a book containing an introduction defining all types of gambling and nine chapters (including chess, backgammon, pachisi, etc) about inventors, masters and tricks of the games and an epilogue in the name of Nasser-al-Din Shah.

Enthusiasm for and addiction to games had become so pervasive that a few years later, "His Excellency, the Great Chancellor plays backgammon!" (Zahir-ul Doleh, 1972) amid the turmoil of Constitutional Revolution and the chancellor's conduct is reprimanded by this writer; indeed, it should be remembered that foreign games also pervaded in the society to the extent that one of the hobbies of Amin-ul Sultan, the Great Chancellor who spent most of his free time gambling, had been playing billiard (Hedayat, 2006).

Obviously, games were also widespread among the middle- and lower-classes of the society; however, since the works from this age are written about the courtiers, our information is limited to the actions of that particular class of society. The people around the court were not an exception to this; "the watchmen are most of the time busy playing cards." (Orsel, 1974) and "eunuchs in imitation of royal servants and the Great Chancellor are busy playing all kinds of gambling, chess or board games. Now, in the imperial court of the honorable government, two third of the time is spent on gambling." (Itemad-u Saltaneh, 1966). In this article, we have taken a glance at 
some of these games in Qajar era and attempted to cast some light on their darker corners; time, venue, extensiveness, customs and the reflection of these games in the literature of the time have directed our efforts in this research. The basis of our work has been works written in that age and itineraries of orientalists who had travelled to Iran during the Qajar period. Indeed we do not claim that a complete observation has been made because not all the sources about that period have been published.

Chess, backgammon, aas bazi (playing aces), ganjafeh (cards), and qaap bazi ${ }^{1}$ are games we have pondered on. In the texts of this period, which mainly reflect court affairs, these games are frequently mentioned and as Pollack says, "chess is very much favored by the aristocratic class," (Pollack, 1982) and in part of a poem, Naqib-ul Mamalek, Nasser-al-Din Shah's storyteller who also has some poetry, says, "kingly game ought to be board or chess and $\boldsymbol{A A S}$ " (Naqib-ul Mamalek). From the five games mentioned above, there were debates about the legitimacy or illegitimacy of chess and backgammon games and were considered almost permissible (Pollack, 1982), but jacks (qaap bazi), ganjafe, and aas bazi were considered gambling, hence their illegitimacy. Of course, it should be noted that all games involving losing and winning money were considered haraam ; therefore, above mentioned games, which involved winning and losing, were also considered haraam games. Chess and backgammon are well known, but ganjafeh, aas bazi, and jacks (qaap bazi) require more explanation. Card games played in that time included aas baazi (aces) and ganjafeh; ganjafeh was more native and "its cards, unlike common cards, were made in Iran" (Wills, 1989) and consisted of ninety cards "every eight of which were illustrated differently from other cards and playing them did not require thinking and creativity" (Chardin, 1993).

Aas bazi has been described in the itineraries of travelers as "one of the oldest card games. These cards are made of small, rectangular, ivory pieces in which beautiful miniatures are illustrated in golden colors; these ivory pieces, some of which are still found, were later replaced by illustrated and varnished cardboards with 5 five-card sets called king, ace, queen, $\boldsymbol{L A K \boldsymbol { A } T}$ and jack each distinguished from others with its yellow, green, red, black or golden background (D'almani, 1956) and Brugesche give a more accurate description of Aas cards: "Iranian cards which are made of cardboards have five types of illustrations with four special signs which add up to twenty cards. These cards' quintuplet of illustrations is organized in the same form of the European cards with the first one depicting the picture of a snake coiling itself around the Lion and Sun symbol; the second card is the king similar to the European card; the third card is the queen with a mother and child drawn on it; the fourth card is jack which is similar to the European jack and shows the head of a soldier, and the fifth card is Lakat which depicts a dancing woman and has no parallel in European cards. Iranians love playing aas and in addition to this, chess and backgammon are also among their most common hobbies." (Brugesche, 1989).

Qaap bazi was a game played with a cube-shaped piece of bone plucked from the leg of a sheep; qaap (=qaab) which has four faces each having a different score, is similar to the common dice. The qaap was thrown in the air and the person who succeeded in having the desired face would be considered winner.

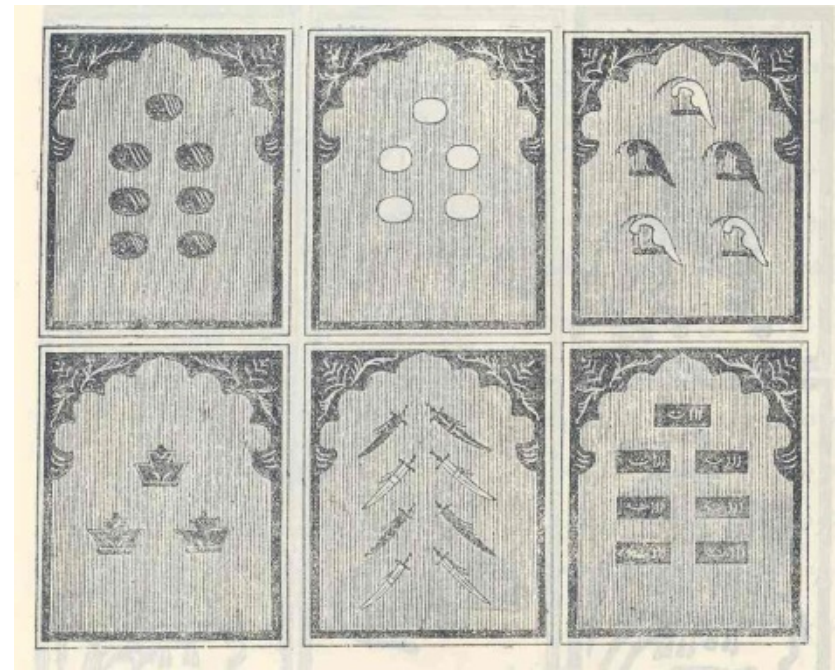

Figure 1. Illustrated ivory pieces used by Iranians as cards (D'almani, 1956) 


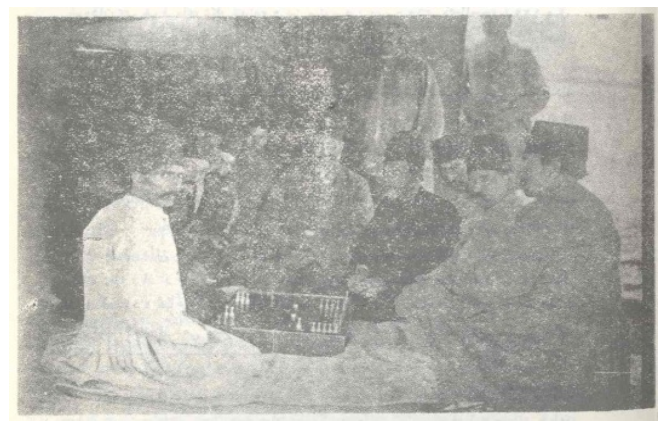

Figure 2. An opaque photo of Nasser-al-Din shah playing chess (Bamdad, 2008)

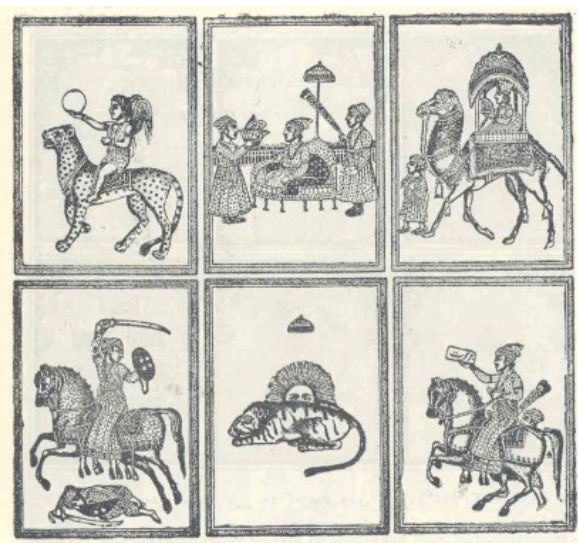

Figure 3. Illustrated ivory pieces used by Iranians as cards (D’almani, 1956)

\section{Extensiveness}

Extensiveness of these games in the Qajar era was so high that a glimpse at the diaries of Amin Lashkar or Muhammad Ali Foroughi astonishes the reader; it is as if their entire time was spent on playing. These games were so variegated that Hedayat the Mokhber-ul Saltaneh became determined to collect them in a book (Hedayat, 2006), but failed to do so.

Pervasiveness of the games gradually enabled some of the prominent dignitaries of the time to gain unbelievable mastery in a certain game; Qajar statesmen had become so dexterous in some games that Amir Nizam Garusi, a master among his peers in chess playing (Mo'ayyer-ul Mamalek, 2011), rivaled with Napoleon III (Ibid, 1976) as did Mehdi Qoli Khan the Majd-ud Doleh with Lord of Salisbury (Ibid, 1976). Indeed, it has been said that Iranians' method of playing differed with that of Europeans as it is the case with Majd-ud Doleh who in the presence of the king played chess with the Lord of Salisbury, several times chancellor of UK, and lost the game and said, 'I was not acquainted with European style of playing. Had we played in our own way I would have won.' His protest was interpreted for the Lord and the Lord, who flaunted his chess playing, stated, 'tell me the difference between the two; after getting acquainted I am prepared to play in your way.' They played another set and the Lord lost the game (Mo'ayyer-ul Mamalek, 2011).

However, Pollack believes that there is no difference between Iranian and European chess playing rules (Pollack, 1982).

There were even exaggerations about the skill of players as Zell-ul Sultan, Nasser-al-Din Shah's son claimed that he had never lost a chess game (Feuvrier, 1987).

Among these games, Nasser-al-Din Shah was had a penchant for backgammon and gambling. From among former Qajar kings, it is been mentioned in the biographies of Fathali Shah Qajar that he played AAS on horseback and "distributing and collecting cards, and giving and taking of lost and won items were done by attendant footmen" (Mostofi, 1981). Knowing the games and having skill in them brought about distinction and privileges, but conversely, not knowing the game was considered some kind of backwardness and ignorance; thus, courtiers gained favor by perfecting their skills. They believed that for chess playing considerable intelligence was needed and since they considered chess as an improver of intelligence and memory, it was more 
highly regarded than board games and for this reason, Mozaffar-uddin Shah, who was slow in learning chess, was denounced (Hedayat, 2006).

Among the aristocrats, most games were played with sumptuous bets. Winning and losing was mostly based on wagering money, sometimes estates and farms and once in a while "the wager was women" (Pollack, 1982). Precious items such as gold and turquoise rings were not an exception in these competitions.

It has been said that the wagers were determined before the game, and princes and dignitaries invited to the presence of the kings were informed about the sum they had to carry on them for the game (Pollack, 1982).

In the games played in the presence of the king or the Great Chancellor "the king was always in luck;" it means that players usually resigned fawningly in order to please His Majesty and the perpetual winner was the Shahanshah (Ibid; Itemad-u Saltaneh, 1966).

\section{Different Modes of Playing}

Apart from one-on-one playing which was the customary mode where the king's royal person himself played with someone (Itemad-u Saltaneh, 1966), one common playing manner in individual games was group playing; in this mode, they took either of these two courses: if an opponent defeated all other opponents, the defeated contrived to compete against the winner as a team, i.e. one person, as a representative of the team, played solely against the opponent and enjoyed the advices of his companions; skillful and solo chess playing of the Afghan man against Nasser-al-Din Shah's team of courtiers is an instance of this case (Mo'ayyer-ul Mamalek, 1983).

In another mode, the two teams competed against each other, but the game was played between two representatives from each group and the kings observed their actions (Mo'ayyer-ul Mamalek, 2011; Itemad-u Saltaneh, 1966; Hedayat, 2006).

\section{Venue}

The center of the games was the court and court personages who had financial power were the main participants of game gatherings; outside the court, they were also the main supporters and the center of gamblers' nights. The house of Karim Shireh-I, Nasser-al-Din Shah's famous fool, was another gathering place outside the court for the contenders (Nasser-al-Din Shah, 1999).

In this period, unlike Safavid age, we no longer see overt playing of games in coffeehouses; if there had been any such cases, they have been played clandestinely and we have no information about them. Violators of gambling prohibition law were severely punished and as Pollack observes, "if sentinels catch people gambling, flogging is certain" (Pollack, 1982). But this strictness should not be taken very seriously for it was easily circumvented or covered by giving bribes; infringements of the law were so extensive that it was announced in the newspaper that "some certain people ran gambling houses with the permission of officers and committed unlawful actions and officers ignored their actions by receiving some amount of money," therefore, the king commanded that "from then on, officers or other enforcers of law should by no means ask for money and those actions be totally prohibited" (Sa'dvandian, 2001).

\section{Time}

Games were usually played at nights when men were free of their daily work and continued well into midnight and sometimes into the morning after. In Ramadan, it had another atmosphere; as it has been reported, "Ramadan is the spring of gambling. In no other month is there so much gambling. In all cities of Persia, it is customary to gamble at Ramadan nights" (Eyn-u Saltaneh, 1998; Shahri, 1992; Divanbeygi, 2003). This was reprimanded at that time because the month of prayers and worshipping had transformed into a month of sins (Adib-ul Hokama, 1985).

At the Shah's court, certain time was specified for playing during celebrations or hunting and some of the high-ranking people or princes were invited to play (Pollack, 1982).

\section{Customs}

\subsection{Democracy}

It is needless to say that in the patriarchal society of Iran, these games were prevalent among men and the reason is quite clear; women were assumed to be weak in terms of bodily and reasoning powers and if it was possible for them to play, there were some trivial games for them; in the customary humiliation and ridiculing of men, the rival was taunted by describing his abilities as fit for women's games. For example, there are some sentences in Ghomarnameh as follows:

"This game (pachisi which was a rather simple game) is, in fact, a game for women, children and credulous merchants" (Ghomarnameh); or "since this is a game of women and children, they had no knowledge or 
creativity to contrive a trick or think of an innovation" (Ibid, 1976). Beside the author's constant differentiation between man and woman, in his categorization, he ascribes trivial games to women and children, and complex and difficult games for the "intelligentsia"; but we should add that there are evidences of women (of course, court women) playing backgammon and chess in Qajar era (Nasser-al-Din Shah; 1999, 1998), but this rarely happened and altogether we may conclude that simple games were specific to women.

\subsection{Observance of Religious Rules}

It is interesting that when playing, people were committed to some religious traditions and beliefs; abstaining from gambling in the direction of kiblah was one of them (Ghomarnameh). Furthermore, since the money they won was regarded as unclean, they distributed among people (Amin Lashkar, 1999); at the court, this money was given out to the servants and valets (Pollack, 1982). It seems as if they were averse to spending this money and as Chardin has depicted, in the Safavid age, the income from brothels was spent on lighting city street torches so that in this way, that sinful money would go up in smoke (Chardin, 1966)!

\subsection{Incidents and Quarrels}

As there are evidences from the old times, trash talk was one of the requirements of games which sometimes led to fights (Onsor-ul Ma'ali, 2001; Mo'ayyer-ul Mamalek, 2011). It was customary to ask the gambler who could not pay the wager to do demeaning and shameful things in order to degrade him and thereby please the winner; gamblers usually started a fight over a fake card and they would almost tear each other apart with their daggers; if an unfortunate man lost the wager and was insolvent, he would struggle with all his might to free himself from the dog fastened to his neck biting him (Orsel, 1974).

If looti (an honorable) man lost the gamble and had not money to pay his debt, the creditor would ask him to rise and three times touch the wall with his back, especially a little lower than his wait shawl, and say "looti has not lost", the creditor would give up his money; but most looties did not tolerate this degradation and found the money wherever they could and paid their wager. It occurred frequently that the looti plucked one hair from his mustache and gave to the creditor as a pledge, and the creditor not only accepted it, but displayed it to everybody and kept it in a clean paper because he was sure that this pledge was a better security than any gold, silver and jewelry (Mostofi, 1981; Shahri, 1992).

\section{Reflection in Literature and Politics}

Games had so permeated in the society that they were readily used in daily events and with them people expressed their intentions and were easily understood; games were also used in political events; in one instance, Ahmad Khan, son of Baqer Khan the Tangestani confronts the English with his troops; secretary of English consulate in Bushehr sends a letter thick with intimidations and humiliation to Ahmad Khan the Tangestani; Ahmad Khan replies him with the following poem:

Ahmad, oh king of the good,

May the mother fortune be your companion,

We are four aces and do not fear,

Your three harlots (Lakkat; my parentheses) and the two jacks (Bamdad, 2008).

As you can see, Ahmad Khan, by playing with words in his poem, humiliates enemy troops; in yet another case, in the dispute between Abdul Ali Mirza, son of Farhad Mirza the Itemad-u Saltaneh, and Jahan Shah Khan Afshar Khamsei, Khan Afshar rebukes Abdul Ali Mirza with the following lines:
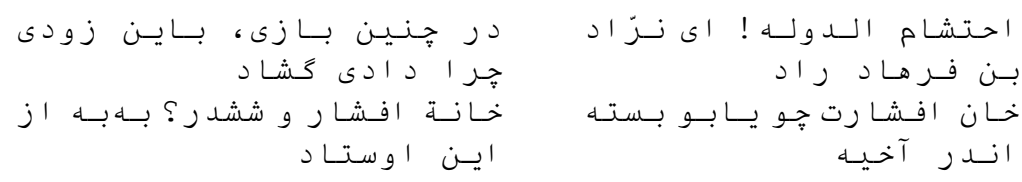

(Mostofi, 1981; Bamdad, 2008).

The versifier uses a subtle pun in Khan-e Afshar and beautifully connects some expressions from backgammon (shehsdar, goshad, narraad, and khan-e afshar). Since literature like a mirror reflects the incidents and people of the society, we also find in the poetry of this age's poets considerable usage of game expressions. Among the trained poets of this period who attained perfection in the Constitutional Age are two renowned poets, Adib-ul Mamalek and Nasim-e Shomal in whose divans there are poems which contain major idioms from these games and they are important in this regard. 
Nasim-e Shomal has written, in his usual method of mixing humor with seriousness, a poem called "Saqi Nameh"3 in which he admonishes gambling and it is very important because of its including most of the gambling expressions. We reproduce as an example some parts of that poem:

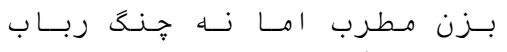

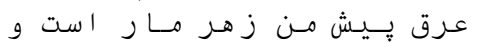

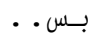

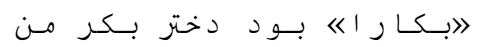

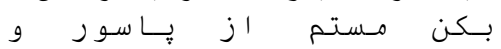

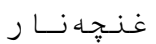

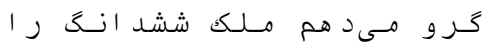

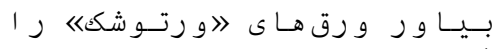

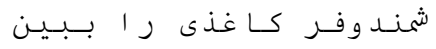

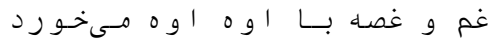

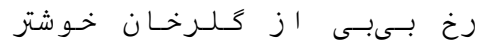

$$
\begin{aligned}
& \text { است }
\end{aligned}
$$

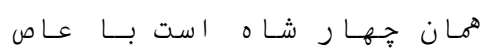

$$
\begin{aligned}
& \text { يـان }
\end{aligned}
$$

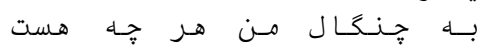

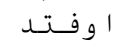

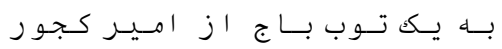

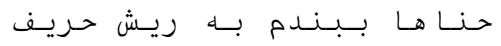

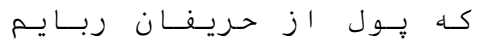

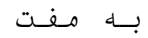

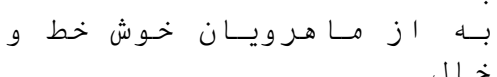

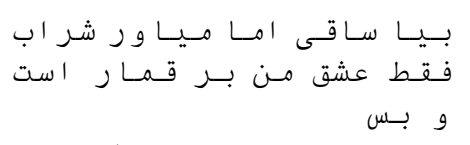

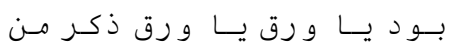

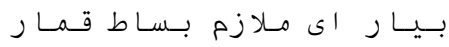

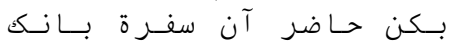

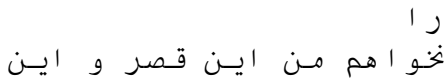

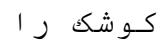

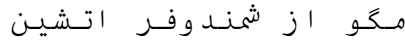

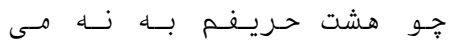

$$
\begin{aligned}
& \text { خـو رد }
\end{aligned}
$$

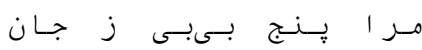

$$
\begin{aligned}
& \text { خـوشتر است است أنس }
\end{aligned}
$$

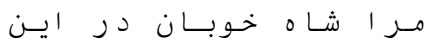

$$
\begin{aligned}
& \text { روزئار }
\end{aligned}
$$

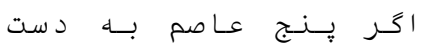

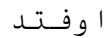

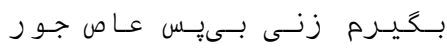

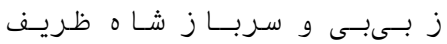

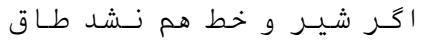

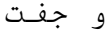

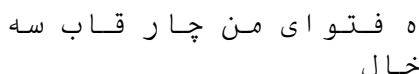

(Husseini, 1953).

Adib-ul Mamalek's Divan is also full of gambling idioms. One of the feats achieved by Adib is versifying idioms and names of months, days, etc. in the style of Nesab-ul Sebyan and his aim was to facilitate the learning and memorizing of difficult words and expressions for the reader; through this endeavor, some considerable number of gambling idioms are left. Adib, following the style of shahrashubs ${ }^{4}$, has written continuous quatrains in which he introduces gambling terminology and idioms (Adib, 1976, XXVIII and XXIX; p. 741); we quote three samples of these quatrains below:

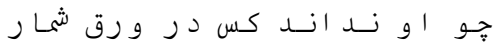

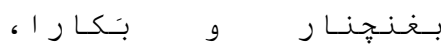

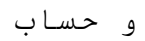

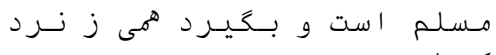

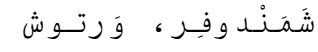

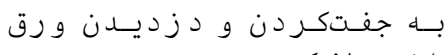

(Ibid, 1976);

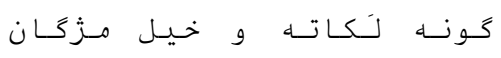

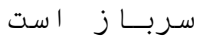

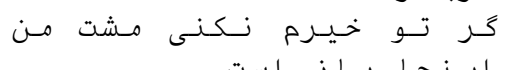

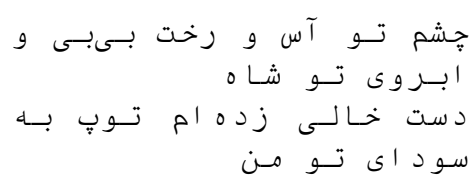

(Ibid, 1976);

$$
\begin{aligned}
& \text { دور ايسن بـازى دلم بــ شور } \\
& \text { آو دورى }
\end{aligned}
$$

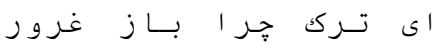

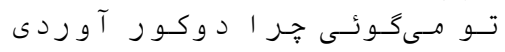

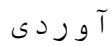

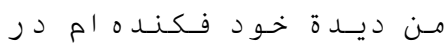

$$
\begin{aligned}
& \text { نـظرت }
\end{aligned}
$$

(Ibid, 1976, Miscellany, XXIX). 


\section{Conclusion}

In this article, by providing several evidences, we looked into a small part of the history and culture of Qajar era and found out that one of the common recreational hobbies among courtiers had been gambling, and despite evident infringement of religious laws, commitment to religion was silently observed. However, by increasing of the popularity of games, skill and mastery in one of the games brought about social prestige for the player, therefore, dignitaries strived to know more and achieve more dexterity in games. Thus, a particular culture formed in the society following game gatherings.

In addition, it is not exaggeration to say that one of the factors causing the socio-cultural deterioration of Qajar era was this very issue and paying excessive attention to amusements which usually ended in losing considerable sums, and the amount of time which had to be allocated to attending to people's affairs and problems was wasted with hours of continuous playing.

\section{References}

Adib-ul, H. (1985). The conversation of the stone and the jug (1st ed.). Tehran: Tarikh- Iran Publications.

Adib-ul, M., \& Farahani, S. K. (1976). The Divan (1st ed.). Tehran: Marvi.

Amin, L. G. I. Y. (1999). In I. Afshar, \& M. R. Daryagasht, The diary (1st ed.). Tehran: Asatir.

Bamdad, M. (2008). Biography of Iranian dignitaries during the 12th, 13th and 14th centuries (6th ed.). Tehran: Zovvar.

Brugesche, H. (1989). A trip to the court of Nasser-al-Din Shah (2nd ed.). Tehran: Ettela'at.

Chardin, J. (1993). The itinerary (1st ed.). Tehran: Toos.

D'almani, H. R. (1956). Itinerary: from Khorasan to Bakhtiari, Tarjemat-un Farrah Vashi (Homayun, Trans.). Tehran: Amir Kabir.

Divanbeygi, M. H. (2003). In I. Afshar, \& M. R. Daryagasht, Memoirs of Divanbeygi. Tehran: Asatir.

Durant, W. A. (1989). An introduction to history of civilizations (2nd ed.). Tehran: Islamic Republic Education Organization Publication.

Eyn-u Saltaneh, G. M. S. (1999). In M. Salor, \& I. Afshar The diary (1st ed.). Tehran: Asatir.

Feuvrier. (1987). In A. E. Ashtiani, \& H. Shahidi, Three years at the Persian court (2nd ed.). Tehran: Donyay-e Ketab.

Hedayat, M. Q. (2006). Khateraat va Khataraat (6th ed.). Tehran: Zovvar.

Husseini, S. A. D. (1953). Ketab-e Baq-e Behesht. Tehran: Elmi.

Itemad-u Saltaneh, M. H. K. (1966). The diary (1st ed.). Tehran: Amir Kabir.

Khanshaqaqi, H. (1974). Memoirs of Momtahen-ud Doleh (1st ed.). Tehran: Amir Kabir.

Mo'ayyer-ul Mamalek, D. A. (1983). Notes from the private life of Nasser-al-Din Shah (1st ed.). Tehran: Tarikh-e Iran Publications.

Mo'ayyer-ul Mamalek, D. A. (2011). Dignitaries of the Qajar age (1st ed.). Tehran: Tarikh-e Iran Publications.

Mostofi, A. (1981). My biography (2nd ed.). Tehran: Zovvar.

Nasser-al-Din, S. (1998). In F. Qaziha, Diary of my First trip to Europe (1st ed.). Tehran: Iranian National Documents Organization.

Nasser-al-Din, S. (1999). In P. Badi'I, The diary (1st ed.). Tehran: Iranian National Documents Organization.

Onsor-ul Ma'ali, K. (2001). In G. Yusofi, Qabus Nameh (11th ed.). Tehran: Elmi VA Farhangi.

Orsel, E. (1974). Orsel's itinerary. Tehran: Sahami-e Khas.

Pollack, E. J. (1982). Pollack's itinerary (1st ed.). Tehran: Kharazmi.

Sa'dvandian, S. (2001). Avvalinhay-e Tehran (1st ed.). Tehran: Ministry of Islamic Guidance and Culture.

Shahri, J. (1989). Social history of Tehran in the 13th century (1st ed.). Tehran: Rasa.

Shahri, J. (1992). The old Tehran (1st ed.). Tehran: Moin.

Wills. (1989). Iran, one century before (1st ed.). Tehran: Iqbal.

Zahir-ul Doleh, A. I. M. (1972). In I. Afshar, Memoirs and documents (1st ed.). Tehran: Pocket Books. 


\section{Notes}

Note 1. A game similar to jacks.

Note2. Religiously prohibited.

Note 3. Book of the Saki.

Note 4. Poets who praise or rebuke city dwellers. 